\title{
Optimization of Fermentation Parameters for Laccase Production by a Novel Deuteromycete Fungus Myrothecium Verrucaria NF-05 Using Response Surface Methodology
}

\author{
Zhao Dan ${ }^{1,2, a}$, Sun Yanyang ${ }^{1, b}$, Du Renpeng ${ }^{1, c}$, Zhang \\ $\mathrm{Li}^{1, \mathrm{~d}}$, Ge jingping*1,2,e \\ ${ }^{1}$ Key Laboratory of Microbiology, Life Science Department, \\ Heilongjiang University, Harbin 150080, China \\ ${ }^{2}$ Engineering Research Center of Agricultural Microbiology
}

\begin{abstract}
To obtain the maximum production of laccase from a novel deuteromycete fungus Myrothecium verrucaria NF-05, optimization of fermentation parameters was performed. Central composite design and response surface analysis revealed the optimum concentration of glucose, $\mathrm{CuSO}_{4}$ and gallic acid to be $26.47 \mathrm{~g} \mathrm{~L}^{-1}, 236.3 \mu \mathrm{M}$, and $138.4 \mu \mathrm{M}$, respectively. This optimization strategy led to the enhancement of laccase production from 12.00 to $19.94 \mathrm{U} \mathrm{mL}^{-1}, 1.66$-fold increase.
\end{abstract}

Keywords-laccase; deuteromycete; medium; optimization; response-surface methodology

\section{INTRODUCTION}

Laccases (EC 1.10.3.2; benzenediol: oxygen oxidoreductase) are a family of multicopper oxidases that were first isolated from Rhus venicifera, the Japanese lacquer tree [1]. Laccases are able to catalyze direct oxidation of ortho- and para-diphenols, amino phenols, polyphenols, polyamines, and aryl diamines as well as some inorganic ions [2]. Due to its broad substrate specificity, laccase has great potential in varied environmental applications including pulp delignification, textile dye bleaching, xenobiotics degradation and biopolymer modification [3-5]. Deuteromycetes fungi possess more advantages in regards to producing laccase, such as simple life cycle, short growth phase and facility to genetic reconstruction. Reports about laccase producing by duteromycetes fungi mainly focus on lignin degradation [6, 7], inducement and purification [8-10] and decolorization of dye [11]. The significant factors which effected laccase production could be investigated by applying response surface methodology (RSM), which enables the study of interaction effects among different variables. Regression model could predict purpose response under untested sets of variables. RSM has been widely reviewed and proven to be efficacious for the production of industrial enzymes during fermentation of microorganisms [12-14].

Optimization of the fermentation process of laccase production by RSM has been reported in the case of different microorganisms $[15,16]$. To the best of our best knowledge there are no reports studying the use of statistical design of experiments (DOE) in regards to the optimization of laccase from deuteromycetes. In this paper
Technology, Ministry of Education, Harbin 150080, China

azhaodan4u@163.com, bsunyanyang1991@126.com, cdurenpeng20096292@163.com, dzl82338244@163.com, egejingping@126.com Corresponding author: gejingping@126.com

we report on the effectiveness of laccase production by a novel deuteromycete fungus Myrothecium verrucaria NF-05 and its optimization using DOE concepts.

\section{MATERIALS AND METHODS}

\section{A. Microorganism}

The microorganism used was deuteromycete fungus Myrothecium verrucaria NF-05, isolated from soil samples in Liangshui Nature Reserve, China and identified by the Department of Microbiology, College of Life Science, Northeast Forestry University. This strain was stored as spore suspension at $-20^{\circ} \mathrm{C}$ in sterile $20 \%$ (v/v) glycerol solution.

\section{B. Shake flake culture}

All the cultures were grown in 250-mL Erlenmeyer flasks containing $60-\mathrm{mL}$ fermentation liquid medium (potato $200 \mathrm{~g} \mathrm{~L}^{-1}, \mathrm{~K}_{2} \mathrm{HPO}_{4} 1.0 \mathrm{~g} \mathrm{~L}^{-1}, \mathrm{MgSO} 4 \cdot 7 \mathrm{H}_{2} \mathrm{O} 0.3 \mathrm{~g}$ $\mathrm{L}^{-1}$ ). Concentrations of glucose, $\mathrm{CuSO}_{4}$ and gallic acid are $28 \mathrm{~g} \mathrm{~L}^{-1}, 230 \mu \mathrm{M} \mathrm{L}^{-1}$ and $140 \mu \mathrm{M} \mathrm{L}^{-1}$ respectively. Each flask was inoculated with three 0.7 -cm-diameter plugs taken from an agar plate (made up of basal potato-glucose medium, potato $200 \mathrm{~g} \mathrm{~L}^{-1}$, glucose $20 \mathrm{~g} \mathrm{~L}^{-1}, \mathrm{~K}_{2} \mathrm{HPO}_{4} 1.0 \mathrm{~g}$ $\mathrm{L}^{-1}$, MgSO $4 \cdot 7 \mathrm{H}_{2} \mathrm{O} 0.3 \mathrm{~g} \mathrm{~L}^{-1}$, agar $20 \mathrm{~g} \mathrm{~L}^{-1}$ ), covered with fungal mycelium and grown for ten days. All cultures were incubated at $28^{\circ} \mathrm{C}$.

\section{Enzyme assay}

Cell-free culture fluid, obtained after removal of mycelium by centrifugation ( $8000 \mathrm{rpm}$ for $15 \mathrm{~min}$ ), was used as the source of the enzyme. The activity of laccase was spectrophotometrically determined by applying $50 \mu \mathrm{L}$ of culture filtrate which was diluted appropriately into $1 \mathrm{~mL}$ of $1 \mathrm{mM}$ ABTS (2,2'-azino-bis-[3-ethyl benzothiazoline-6-sulphonic acid]) (SIGMA) in $0.2 \mathrm{M}$ acetate buffer ( $\mathrm{pH} 4.0)$ to get the absorbance in readable range. The reaction mixture $(4 \mathrm{~mL})$ was incubated in $30^{\circ} \mathrm{C}$ for 3 min based on Wu et al.'s method [17]. One unit of enzyme activity was defined as $1 \mu \mathrm{mol}$ of ABTS oxidized per minute. To calculate enzyme activity the absorption coefficient $\varepsilon_{420} \mathrm{~nm}=3.6 \times 10^{4} \mathrm{M}^{-1} \mathrm{~cm}^{-1}$ was used.

\section{Experimental designs and data analysis}

Laccase production can be written as a function 
(response surface) of coded values of variables with a significant influence on laccase production, and can be approximated by a second-order polynomial. CCD (Table 1) is a useful tool to acquire data to fit this polynomial $(Y, \mathrm{U}$ $\left.\mathrm{mL}^{-1}\right)$. All the experiments were performed in triplicates according to a design matrix. The statistical software Design Expert (version 7.0.0, Stat-Ease, Minneapolis, USA) was used for experimental design and data analysis.

\section{RESULTS}

The results of regression analysis are shown in Table 2 . $F$-test for the analysis of variance done on the experimental data indicated that the model was highly significant, with $F$-value of 120.16 and $P>F$ of 0.0001 ; the obtained model was adequate. The model had an $R^{2}$ value of 0.9914 , indicating a good correlation between observed and predicted responses. Also, the model indicated that the predicted $R^{2}$ value of 0.9817 was in reasonable agreement with the adjusted $R^{2}$ value of 0.9155 . The results demonstrated that glucose was found to have the most significant effect on laccase production by Myrothecium verrucaria NF-05, as indicated by a $P>F$-value of 0.0001 . $\mathrm{CuSO}_{4}$ and gallic acid had significant linear effects on the system. Interactions between glucose and $\mathrm{CuSO}_{4}$ as well as $\mathrm{CuSO}_{4}$ and gallic acid also had significant effects $(P>$ $F \leq 0.05$ ). The maximum point of the model can be obtained: $26.47 \mathrm{~g} \mathrm{~L}^{-1}$ of glucose, $236.3 \mu \mathrm{M}$ of $\mathrm{CuSO}_{4}$ and $138.4 \mu \mathrm{M}$ of gallic acid (coded level -0.51, 0.21 and -0.08, respectively). The model predicted a maximum response of $19.82 \mathrm{U} / \mathrm{mL}^{-1}$ for this point. The results were confirmed by additional shake flask experiments using parameters representing this maximum point and a value of $19.94 \pm 1.16$ $\mathrm{U}^{\mathrm{mL}^{-1}}(N=6)$ was obtained. Good correlation between these two results verified the validity of the response model and the existence of an optimal point.

TABLE 1 EXPERIMENTAL DESIGN AND RESULTS OF THE CENTRAL COMPOSITE DESIGN

\begin{tabular}{cccccc}
\hline \multirow{2}{*}{ Run } & $\mathrm{X}_{1}$ & $\mathrm{X}_{2}$ & $\mathrm{X}_{3}$ & \multicolumn{2}{c}{ Laccase $\left(\mathrm{U} \mathrm{mL}^{-1}\right)$} \\
& -1 & -1 & -1 & 8.21 & 8.46 \\
1 & -1 & 1 & 1 & 12.27 & 12.39 \\
2 & -1 & -1 & 1 & 7.91 & 7.71 \\
3 & 1 & -1 & 9.48 & 8.68 \\
4 & 1 & 1 & 9.63 & 10.36 \\
5 & -1 & -1 & 1 & 14.87 & 14.99 \\
6 & -1 & 1 & -1 & 7.65 & 7.45 \\
7 & 1 & -1 & -1 & 5.21 & 4.89 \\
8 & 1 & 1 & 1 & 17.28 & 16.49 \\
9 & -1.633 & 0 & 0 & 8.26 & 9.16 \\
10 & 1.633 & 0 & 0 & 7.96 & 7.57 \\
11 & 0 & -1.633 & 0 & 9.90 & 10.41 \\
12 & 0 & 1.633 & 0 & 10.16 & 10.51 \\
13 & 0 & 0 & -1.633 & 9.01 & 8.77 \\
14 & 0 & 0 & 1.633 & 19.53 & 19.07 \\
15 & 0 & 0 & 0 & 18.83 & 19.07 \\
16 & 0 & 0 & 0 & 19.53 & 19.04 \\
17 & 0 & 0 & 0 & 19.23 & 19.27 \\
18 & 0 & 0 & 0 & 18.78 & 19.04 \\
19 & 0 & 0 & 0 & 18.89 & 19.27 \\
20 & 0 & 0 & 0 & & \\
\hline
\end{tabular}

\section{DISCUSSION}

Contour plots of laccase were generated and analyzed for determination of the optimal levels of the variables and their interaction effects (Fig. 1). Wholly speaking, glucose, $\mathrm{CuSO}_{4}$ and gallic acid were synergic in the biosynthesis of laccase. Concentrations of glucose between -1 and 0 of coded level brought the highest yields of laccase production regardless of other factors. The secretion of laccase has been proven to be coupled with mycelium growth [18]. Lower glucose concentrations might cause a deficiency of mycelium growth, which would limit the laccase activity. Too much glucose did not enhance the laccase activity and instead lower activities were obtained. Nevertheless, high concentrations of glucose have been found to repress laccase genes in fungi [19], which might be an energy-saving response [20].

TABLE 2 RESULTS OF THE REGRESSION ANALYSIS OF THE CENTRAL COMPOSITE DESIGN

\begin{tabular}{llll}
\hline Item & \multicolumn{3}{l}{ Regression analysis } \\
\cline { 2 - 4 } & Coefficient & F-value & Significant level \\
X1 & -2.24 & 110.42 & $<0.0001$ \\
X2 & 0.87 & 19.17 & 0.0024 \\
X3 & -0.53 & 7.11 & 0.0285 \\
X1X2 & -1.27 & 24.44 & 0.0011 \\
X1X3 & -0.35 & 1.89 & 0.2060 \\
X2X3 & -1.12 & 15.31 & 0.0045 \\
X12 & -2.42 & 90.99 & $<0.0001$ \\
X22 & -3.78 & 311.98 & $<0.0001$ \\
X32 & -3.54 & 272.93 & $<0.0001$ \\
R2=0.9914 Adj R2 $=0.9817$ & Pred R2 $=0.9155$ \\
\hline \multicolumn{3}{c}{} \\
\hline \multicolumn{4}{c}{}
\end{tabular}
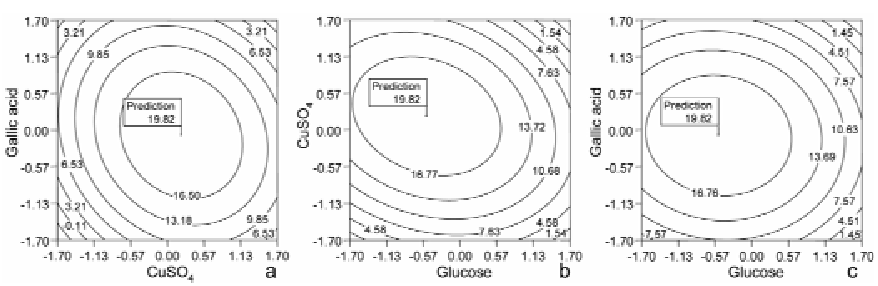

Figure 1. Contour plots of laccase production showing interactive effect of

$$
\begin{aligned}
& \text { (a) } \mathrm{CuSO}_{4} \text { and Gallic acid (b) Glucose and } \mathrm{CuSO}_{4} \text { and (c) Glucose and } \\
& \text { Gallic acid }
\end{aligned}
$$

$\mathrm{CuSO}_{4}$ together with its interactions with glucose and gallic acid had significant effects in this study $(P>F$-value of $0.0024,0.0011,0.0045)$. It is demonstrated that copper is an important inducer for laccase production which is in agreement with Gnanamani et al.'s report [21]. The yield of laccase was found to be higher with the coded level of $\mathrm{CuSO}_{4}$ ranging from 0 to 0.5 and optimum concentration of $236.3 \mu \mathrm{M}$, which corresponds with the concentrations typically used in cultivation media $(2-600 \mu \mathrm{M})$ for laccase production in wild-type or recombinant strains [22-24]. Several probable mechanisms have been proposed, i.e., regulating laccase expression at transcription level [18], acting in defense mechanism against oxidation pressure [25], formatting metallothioneins or cell-wall components [26]. The optimum concentration of copper varies remarkably among strains. 
As an aromatic compound, gallic acid is a potential inducer of laccase [27, 28]. Gallic acid in a final concentration of $1 \mathrm{mM}$ obviously advanced laccase activity by both Streptomyces psammoticus [29] and white rot fungus WR-1 [28]. Nevertheless, higher levels of gallic acid seemed obstructive in this study. The optimum concentration was $138.4 \mu \mathrm{M}$ around medium coded level when $\mathrm{CuSO}_{4}$ was fixed at 0 to 0.5 of coded level. The deuteromycete fungus Paecilomyces sp. exhibits an evident decrease in laccase production under cooperative induction by $100 \mu \mathrm{M}$ of gallic acid and the extra addition of $50 \mu \mathrm{M}$ copper [9].

Laccase is the most extensively studied group of enzymes among oxidases and has attracted more and more interest for applications in environmental, food, bioelectronics and lignin degradation. To the best of our knowledge, Myrothecium verrucaria NF-05 is a newly isolated deuteromycete fungus strain without detailed study on fermentation process of laccase production. Myrothecium verrucaria NF-05 produced laccase within a short incubation period of 5-7 days and broad $\mathrm{pH}$ range of 6-8. These remarkable properties make this organism a better candidate for biotechnological applications especially in the areas where alkaline conditions are preferred. Based on present work, the characteristics of the laccase protein should be further studied; taking into consideration the synergistic inducing effects between $\mathrm{CuSO}_{4}$ and gallic acid, and the adding time of inducers.

\section{ACKNOWLEDGEMENT}

The research was supported by the National Science Foundation for Young Scholars of China (No. 31300355) and the National Natural Science Foundation of China (No. 31270534, 31270143, 31470537) and the Distinguished Young Scholars of Heilongjiang University (No. JCL201305) and the Foundation of Harbin Municipal Science and Technology Bureau (No. 2014RFQXJ101).

\section{REFERENCES}

[1] H. Yoshida. J Chem Soc. Vol. 43 (1883), p. 472.

[2] P. Giardina, V. Faraco, C. Pezzella, A. Piscitelli, S. Vanhulle and G. Sannia. Cellular and Molecular Life Sciences. Vol. 3 (2010), p. 369.

[3] A. Suurnäkki, T. Oksanen, M. Orlandi, L. Zoia, C. Canevali and L. Viikari. Enzyme Microb Tech. Vol. 3-4 (2010), p. 153.

[4] M. Sulak, E. Erhan, B. Keskinler, F. Yilmaz and A. Celik. Sens Lett. Vol. 2 (2010), p. 262.
[5] D. Singh Arora, R. Kumar Sharma. Appl Biochem Biotech. Vol. 6 (2010), p. 1760 .

[6] B. Kluczek-Turpeinen, M. Tuomela, A. Hatakka and M. Hofrichter. Appl Biochem Biotech. Vol. 4 (2003), p. 374.

[7] H. Tanaka, S. Itakura and A. Enoki. Biocontrol Sci. Vol. 1 (2000), p. 39.

[8] S. Sadhasivam, S. Savitha, K. Swaminathan and F. Lin. Process Biochem. Vol. 7 (2008), p. 736.

[9] Z. Liu, D. Zhang, Z. Hua, J. Li, G. Du and J. Chen. J Ind Microbiol Biot. Vol. 10 (2009), p. 1315.

[10] Z. Y. Liu, D. X. Zhang, Z. Z. Hua, J. H. Li, G. C. Du and J. Chen. Bioproc Biosyst Eng. Vol. 5 (2010), p. 639.

[11] J. Hao, F. Song, F. Huang, C. Yang, Z. Zhang, Y. Zheng and X. Tian. J Ind Microbiol Biot. Vol. 3 (2007), p. 233.

[12] Y. P. Zhuang, B. Chen, J. Chu and S. Zhang. Process Biochem. Vol. 2 (2006), p. 405.

[13] R. C. S Thys, S. O. Guzzon, F. Cladera-Olivera and A. Brandelli. Process Biochem. Vol. 1 (2006), p. 67.

[14] M. S. Tanyildizi, D. Ozer and M. Elibol. Process Biochem. Vol. 7 (2005), p. 2291

[15] A. F. D. Vasconcelos, A. M. Barbosa, R. F. H. Dekker, I. S. Scarminio and M. I. Rezende. Process Biochem. Vol. 10 (2000), p.1131.

[16] K. N. Niladevi, R. K. Sukumaran, N. Jacob, G. S. Anisha and P. Prema. Microbiol Res. Vol. 1 (2009), p. 105.

[17] Y. Wu, Z. Luo, R. Chow and L. Vrijmoed. Bioresource Technol. Vol. 102 (2010), p. 9772.

[18] S. Ohga, D. Royse. FEMS Microbiol Lett. Vol. 1 (2001), p. 111.

[19] M. Mansur, T. Suarez and A. Gonzalez. Appl Environ Microb. Vol. 2 (1998), p.771.

[20] H. Ronne. Trends Genet. Vol. 1 (1995), p. 12.

[21] A. Gnanamani, M. Jayaprakashvel, M. Arulmani and S. Sadulla. Enzyme Microb Technol. Vol. 38 (2006), p. 1017.

[22] P. J. Collins, A. D. Dobson. Appl Environ Microbiol. Vol. 63 (1997), p. 3444.

[23] J. K. Dittmer, N.J. Patel, S.W. Dhawale and S.S. Dhawale. FEMS Microbiol Lett. Vol. 49 (1997), p. 65.

[24] G. Palmieri, P. Giardina, C. Bianco, B. Fontanella and G. Sannia. Appl Environ Microbiol. Vol. 66 (2000), p. 920.

[25] J. Fernandez-Larrea, U. Stahl. Mol Gen Genet. Vol. 252 (1996), p. 539.

[26] C. Cervantes, F. Gutierrez-Corona. FEMS Microbiol Rev. Vol. 14 (1994), 121

[27] C. Galhaup, H. Wagner, B. Hinterstoisser and D. Haltrich. Enzyme Microb Technol. Vol. 30 (2002), p. 529.

[28] M. Revankar, S. Lele. Process Biochem, Vol. 3 (2006), p. 581.

[29] K. Niladevi, P. Prema. Bioresource Technol. Vol. 11 (2008), p. 4583. 